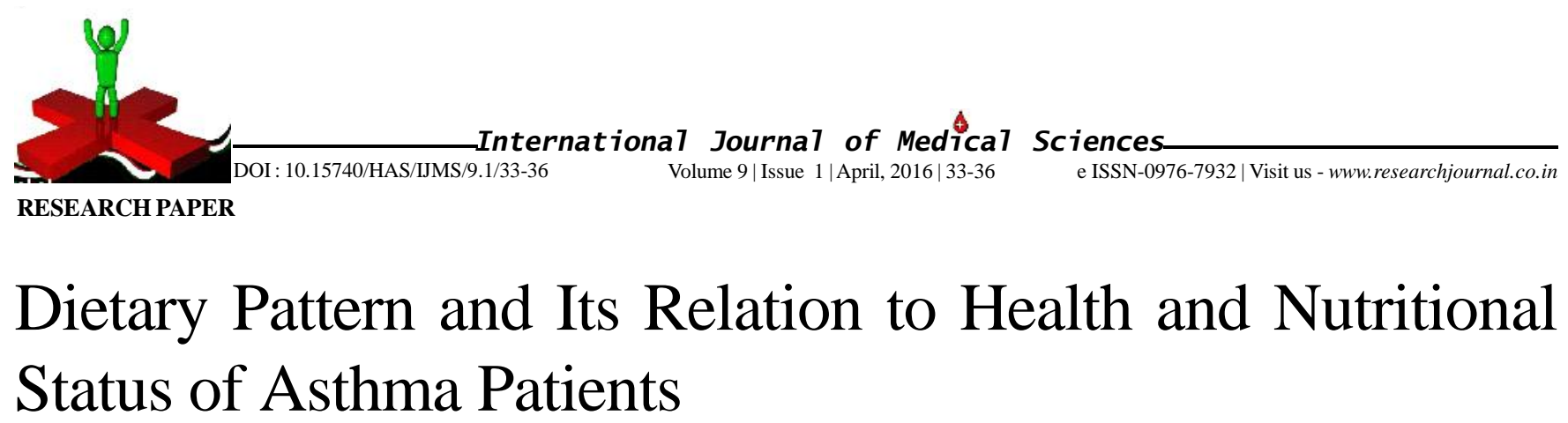

MUKTA SINGH, ANUBHA MISHRA AND ANAMIKA JAIN

Correspondence to :

\section{MUKTA SINGH}

Department of Home Science, Banaras Hindu University, VARANASI (U.P.) INDIA Email: drmuktasingh@ gmail.com

\section{KEY WORDS :}

Asthma, Health, Nutrition, Asthmatic patients, Pulmonary function test

\begin{abstract}
Allergic bronchial asthma is caused by exposure to environmental and dietary allergens. Approximately in every fifth asthmatic patient the possible role of food allergy should be taken into account. The present study consisted of 128 subjects of 40-90 years of age group attending breath easy chest care centre, assighat Varanasi. The data was collected with the help of structured questionnaires on general information e.g. age, sex socio-economic status and occupation and for specific information e.g.history of the illness, food allergy, symptoms, and their nutritional pattern. Anthropometric assessment for height, weight and BMI, laboratory tests and clinical parameters e.g. hemoglobin, TLC, DLC and pulmonary function tests were collected within the duration of two months. In the statistical analysis, percentage, mean and Chi-square test were calculated. Total 83 per cent male and 45 per cent female respondents participated in the present study. 26.5 per cent males and 14.06 per cent females in the study population were suffering from severe asthma. Dust $(41.40 \%)$ was the most common allergen occurred with highest percentage in asthmatics patients and second most allergen which occurs in patients are foods with the percentage of 27.34 per cent. Through food frequency questionnaire it was found that fat intake was mostly consumed by the males $(43.75 \%)$ and females $(27.34 \%)$ respondents. Due to lack of fruits and vegetables in their diet patients were probably suffering from Vitamin C deficiency.
\end{abstract}

How to cite this paper : Singh, Mukta, Mishra, Anubha and Jain, Anamika (2016). Dietary Pattern and Its Relation to Health and Nutritional Status of Asthma Patients. Internat. J. Med. Sci., 9(1) : 33-36. 